\title{
The Effect of Heat Treatment on the Evolution of Microstructure and Texture in Ti80 Hot Rolled Pipe
}

\author{
Shengtong He ${ }^{a, b, c} \mathbb{1}$, Weidong Zeng ${ }^{a, b, c, d *}$, Jianwei Xu ${ }^{a, b, c}$, Dadi Zhou ${ }^{a, b, c}$ \\ ${ }^{a}$ Northwestern Polytechnical University, State Key Laboratory of Solidification Processing, Xi'an, \\ 710072, China. \\ ${ }^{b}$ Northwestern Polytechnical University, School of Materials Science and Engineering, Defense \\ Technologies Innovation Center of Precision Forging and Ring Rolling, Xi'an, 710072, China. \\ ${ }^{c}$ Northwestern Polytechnical University, Shaanxi Key Laboratory of High-Performance Precision \\ Forming Technology and Equipment, Xi'an, 710072, PR China. \\ ${ }^{d}$ State Key Laboratory of Solidification Processing, Northwestern Polytechnical University, Xi'an, \\ 710072, China.
}

Received: June 17, 2021; Revised: September 24, 2021; Accepted: October 31, 2021.

In this study, the microstructure and texture evolution of hot rolled Ti80 pipe annealing at $960^{\circ} \mathrm{C}$ and $990^{\circ} \mathrm{C}$ in $\alpha+\beta$ two-phase field have been investigated. The results showed that the dissolution of $\alpha$ phases induced the increase of texture components of primary $\alpha$ phases $\left(\alpha_{\mathrm{p}}\right)$ and the $\alpha_{\mathrm{p}}$ were the main factors that determine the final texture at $960^{\circ} \mathrm{C}$. At $960^{\circ} \mathrm{C}$, the microtextures of secondary $\alpha$ phases $\left(\alpha_{\mathrm{s}}\right)$ were very close to that of $\alpha_{\mathrm{p}}$. As the annealing temperature increased to $990^{\circ} \mathrm{C}$, the main factors affecting the microtextures of $\alpha_{\mathrm{S}}$ changed from the $\alpha_{\mathrm{p}}$ to the recrystallized $\beta$ grains. The textures of $\beta$ phases were greatly influenced by the annealing temperature. The $\beta$ phases at high temperature were not mainly from the grow up of residual $\beta$ phases. It was formed by the transformation of $\alpha$ phases at room temperature. Consequently, this study could provide some ideas for decreasing the texture intensities of hot rolled Ti80 pipes, such as reducing the area of $\alpha$ colonies before rolling, scattering the crystal orientations of $\alpha_{\mathrm{p}}$, and controlling the size of recrystallized $\beta$ grains.

Keywords: Titanium alloys, Texture, Heat treatment, Electron backscattered diffraction (EBSD).

\section{Introduction}

The near $\alpha$ titanium and its alloys are widely used for structural applications in aerospace, energy related, and marine engineering fields because of their low density, high toughness, high specific strength and good corrosion resistance ${ }^{1-3}$. As a newly developed near- $\alpha$ titanium alloy by China, the tubular product of Ti80 alloys are mainly used in offshore oil drilling and nuclear power field. To obtain a good balance between strength and ductility, the bimodal microstructures composed of equiaxed primary $\alpha$ phases $\left(\alpha_{\mathrm{p}}\right)$ and lamellar secondary $\alpha$ phases $\left(\alpha_{\mathrm{S}}\right)$ are good candidates ${ }^{4}$. It is well known that the mechanical properties including strength, fracture toughness, ductility and fatigue performance are greatly affected by microstructure morphology ${ }^{5-7}$. Generally, increase of the volume fraction of $\alpha_{p}$ could improve the tensile properties and high cycle fatigue performance, but decrease the fracture toughness for bimodal microstructure. In addition, texture is also an important factor affecting the mechanical properties of titanium alloy pipes. The anisotropy of mechanical properties is closely related to macrotexture, which is composed of many microtextures. And the microtexture also has made effect on the nucleation of fatigue cracks. Therefore, it is necessary to study the mechanism of microtextures in Ti80 pipes.

*e-mail: zengwd@nwpu.edu.cn
A comprehensive review of the evolution of texture during thermomechanical processing of titanium and its alloys has been reported by $\mathrm{Singh}^{8}$. In general, titanium alloy forgings undergo a series of thermomechanical processing steps in $\alpha+\beta$ phase fields, followed by $\beta$ to $\alpha$ phase transformation. Therefore, the final texture is determined by processing parameters, such as temperature, mode of deformation (rolling, forging and extrusion), strain, strain rates and cooling rates. And the better understanding of texture forming mechanism induced by every step would be helpful to the establishment of more physically based process modeling. Texture evolution during the hot deformation process has been investigated by previous studies ${ }^{9-11}$. As for phase transformation textures, many researchers mainly focused on the variant selection mechanisms during the cooling from above the $\beta$ transus. Bantounas et $\mathrm{al}^{12}$. found that the formation of microtexure was associated with variant selection during the $\beta$ to $\alpha$ phase transformation. It was found that $\alpha$ phases with the same orientations of c-axis preferred to nucleate on both sides of $\beta$ grain pairs having a common [110] pole in many studies ${ }^{13-15}$. The nucleation of $\alpha$ phases with same orientations would induce the large regions of $\alpha$ texture component after $\beta$ to $\alpha$ transformation. Obviously, the $\alpha$ texture after transformation is closely related to the original $\beta$ grain. G.C. Obasi reported that the intensities of $\alpha$ texture components increased dramatically with the growth of $\beta$ grain size ${ }^{16}$. In Zhao's study, the transformed $\alpha$ texture components were greatly 
influenced by original $\beta$ texture ${ }^{13}$. The stronger (110) $\beta$ texture intensity could provide more neighboring $\beta$ grains with nearly parallel (110) pole. However, very limited research on the texture evolution during the heat treatment in the two-phase region could be found. Germain et al. have investigated the effect of $\alpha_{\mathrm{p}}$ on the texture change by separating the $\alpha_{\mathrm{p}}$ and $\alpha_{S}$ texture and found that major texture component of the $\alpha_{S}$ colonies was very similar with that of $\alpha_{\mathrm{p}}$ in the compression of TIMETAL 834 alloy $^{17}$. The texture produced at different rolling temperatures in $\alpha+\beta$ field and subsequent annealing was systematically analyzed by D.G. Leo Prakash ${ }^{18}$. In D.G's study, the precipitated $\alpha_{\mathrm{S}}$ had the same texture components, although the orientation of adjacent $\beta$ grains had different orientations, which indicates that variant selection was an important factor affecting the texture. Zhao studied the effect of annealing temperature on the texture evolution in the two-phase region ${ }^{19}$. They observed that texture type and intensity were changed with the increasing annealing temperature. However, the initial microstructure was obtained by multiple forging and the primary $\beta$ grain boundary could not be observed before heat treatment. This has made the analysis of texture evolution difficult after heat treatment due to the complexity of the initial texture.

At present, previous researchers have studied the texture evolution and variant selection mechanism of titanium alloys during hot compression and plate rolling. However, the texture of titanium pipe was seldom reported. Although the bimodal microstructure has excellent comprehensive mechanical properties, different morphologies will lead to significant differences in mechanical properties. Therefore, we investigated the effect of microstructure morphology such as the number of $\alpha_{\mathrm{p}}$ and the size of recrystallized $\beta$ grain on the microtexture in the heat treatment of Ti80 pipe. In this work, the Ti80 pipe after hot rolling was annealed at different temperatures in two-phase region to obtain different microstructures. The development of the microtexture during this process was investigated using EBSD methods.

\section{Experimental Procedure}

The exact chemical composition of the alloy used in this study is measured by chemical analysis method, as shown in Table 1. The initial microstructure was Widmannstatten structure, which was obtained by cross piercing in $\beta$ phase field, as shown in Figure 1. The final Ti80 pipe was acquired by hot rolling at $930{ }^{\circ} \mathrm{C}$. The $\beta$ transus temperature was determined to be $1000{ }^{\circ} \mathrm{C}$ by using the metallographic method. The samples were cut along the longitudinal section of the pipe as shown in Figure 2. Two of the samples were annealed at $960^{\circ} \mathrm{C}$ and $990^{\circ} \mathrm{C}$ for $30 \mathrm{~min}$ followed by slow cooling, respectively. The sample surfaces containing rolling direction (RD) and normal direction (ND) were prepared for the analysis of microstructure and texture. The sample surface was prepared by grinding, mechanically polishing and electrolytically polishing with a solution of $6 \% \mathrm{HClO} 4+64 \% \mathrm{CH} 3 \mathrm{OH}+$ $30 \% \mathrm{C} 4 \mathrm{H} 10 \mathrm{O}$ for EBSD observation. The scanning area of the macrotexture is $500 \mu \mathrm{m} \times 200 \mu \mathrm{m}$, and that of the microtexture is $180 \mu \mathrm{m} \times 180 \mu \mathrm{m}$. The step size of the larger areas and smaller areas was $2 \mu \mathrm{m}$ and $0.3 \mu \mathrm{m}$ respectively.

\subsection{Theoretical calculation methods}

As a near $\alpha$ titanium alloy, it is difficult to obtain its crystallographic orientation through EBSD due to the low $\beta$ phase content at room temperature. Therefore, the crystallographic orientation of the $\beta$ phase at high temperature are calculated by the crystallographic orientation of the $\alpha$ phases precipitated during the cooling process. According to the Bunge convention, the crystallographic orientation can be described by a set of Euler angles $(\Phi 1, \Phi, \Phi 2)^{20}$. The rotation matrix $\mathrm{G}$ could be obtained by Eq (1).

$G=\left[\begin{array}{ccc}\cos \Phi 1 \cos \Phi 2-\sin \Phi 1 \sin \Phi 2 \cos \Phi & \sin \Phi 1 \cos \Phi 2+\cos \Phi 1 \sin \Phi 2 \cos \Phi & \sin \Phi 2 \sin \Phi \\ -\cos \Phi 1 \sin \Phi 2-\sin \Phi 1 \sin \Phi 2 \cos \Phi & -\sin \Phi 1 \sin \Phi 2+\cos \Phi 1 \cos \Phi 2 \cos \Phi & \cos \Phi 2 \sin \Phi \\ \sin \Phi 1 \sin \Phi & -\cos \Phi 1 \sin \Phi \ldots & \cos \Phi\end{array}\right]$

The orientation of $\alpha$ grain can be expressed by the matrix $G^{\alpha} . G^{\alpha}$ can be characterized by a set of 12 rotations by

$S_{j}^{\alpha} G^{\alpha}$

where $S_{j}^{\alpha}(\mathrm{j}=1,2, \ldots 12)$ is a set of rotation matrix for the hexagonal system. The BOR between $\alpha$ and $\beta$ can be expressed by

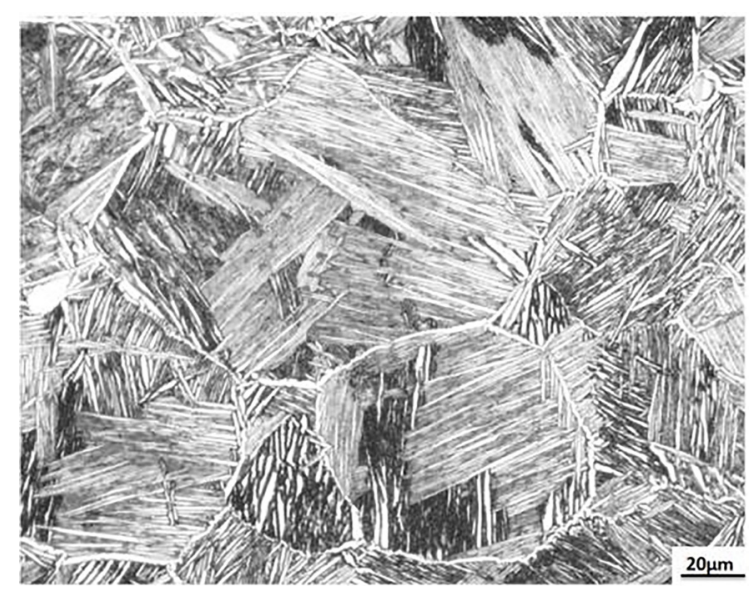

Figure 1. The microstructure of Ti80 pipe before hot rolling.

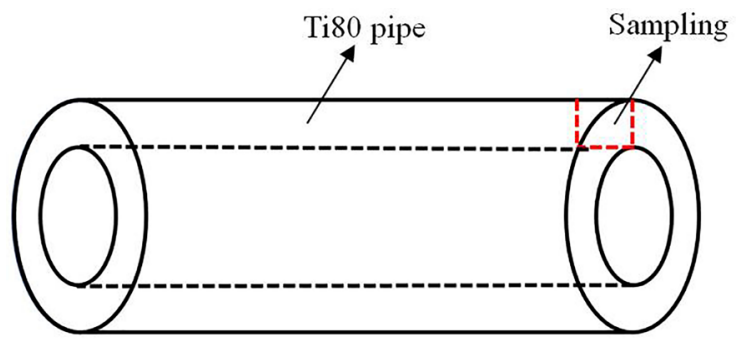

Figure 2. Schematic picture of the sample cut from pipe.

Table 1. Chemical composition of Ti80 pipe used in this study.

\begin{tabular}{ccccccccccc}
\hline Elements & $\mathrm{Ti}$ & $\mathrm{Al}$ & $\mathrm{Nb}$ & $\mathrm{Zr}$ & $\mathrm{Mo}$ & $\mathrm{Si}$ & $\mathrm{Fe}$ & $\mathrm{C}$ & $\mathrm{N}$ & $\mathrm{O}$ \\
\hline Contents & $\mathrm{Bal}$ & 6.12 & 3.1 & 2.07 & 0.94 & 0.03 & 0.02 & 0.005 & 0.001 & 0.10 \\
\hline
\end{tabular}




$$
\mathrm{D}=\left[\begin{array}{ccc}
\frac{1}{2}\left(1+\frac{1}{6^{1 / 2}}\right) & \frac{1}{2}\left(\frac{1}{3^{1 / 2}}+\frac{1}{2^{1 / 2}}\right) & \frac{1}{2^{1 / 2}} \\
\frac{1}{2}\left(1+\frac{1}{6^{1 / 2}}\right) & \frac{1}{2}\left(\frac{1}{3^{1 / 2}}-\frac{1}{6^{1 / 2}}\right) & \frac{1}{2^{1 / 2}} \\
\frac{1}{2}\left(1-\frac{2}{6^{1 / 2}}\right) & \frac{1}{2}\left(\frac{1}{3^{1 / 2}}+\frac{2}{2^{1 / 2}}\right) & 0
\end{array}\right]
$$

Therefore, the orientations of parent $\beta$ grain can be calculated by

$$
D^{-1} S_{j}^{\alpha} G^{\alpha}
$$

Due to the symmetry of the cubic system, all possible orientations of parent $\beta$ grains can be described as follows,

$$
S_{i}^{\alpha} D^{-1} S_{j}^{\alpha} G^{\alpha}
$$

Where $S_{i}^{\alpha}(\mathrm{i}=1,2, \ldots 24)$ is a set of rotational symmetry matrix for the cubic structure.

\section{Results}

\subsection{Microstructure and macrotexture characterization}

The microstructures of the Ti80 pipe after rolling and heat treatment are shown in Figure 3. It could be observed that the original $\beta$ grains were greatly elongated with a width of about $50 \pm 5 \mu \mathrm{m}$ and a length of more than 500 $\pm 50 \mu \mathrm{m}$. The as-rolled microstructure shows that some of the $\alpha_{\mathrm{p}}$ are still lamellar structure and the others have been globularized within prior $\beta$ grains. It indicated that the dynamic globularization occurred and the degree of globularization was mainly affected by the crystal direction of $\alpha$ colonies before deformation ${ }^{21,22}$. Meanwhile, no $\alpha_{S}$ were observed in the picture, which indicated that $\beta$ phase contents were very low during rolling in $\alpha+\beta$ phase region. After annealing at $960^{\circ} \mathrm{C}$, the bimodal microstructure with $20 \%$ volume fraction of $\alpha_{\mathrm{p}}$ was obtained according to the statistics by quantitative metallographic image analysis software. This was because a large amount of $\alpha$ phases was transformed to the $\beta$ phases during the heat treatment in the dual-phase zone. In the subsequent cooling process, the $\beta$ phases were transformed into the lamellar secondary $\alpha$ phases. As the annealing temperature increased to $990{ }^{\circ} \mathrm{C}$, the content of the $\alpha_{\mathrm{p}}$ decreased from $20 \%$ to $9 \%$, and the average size of the recrystallized $\beta$ grains increased from $30 \pm 6 \mu \mathrm{m}$ to 80 $\pm 9 \mu \mathrm{m}$. This could be attributed to the dissolution of more $\alpha_{\mathrm{p}}$ as the annealing temperature increased. Then the pinning effect of $\alpha_{\mathrm{p}}$ on $\beta$ grains was reduced, and $\beta$ grains will further grow up. In addition, it can be seen that the necklace like $\alpha_{\mathrm{p}}$ have been densely distributed along the rolling direction (RD) no matter at $960^{\circ} \mathrm{C}$ or $990^{\circ} \mathrm{C}$, and the distance between the necklace like $\alpha$ phases along the ND direction increases with the increase of annealing temperature. This phenomenon was explained in the section 3.3.
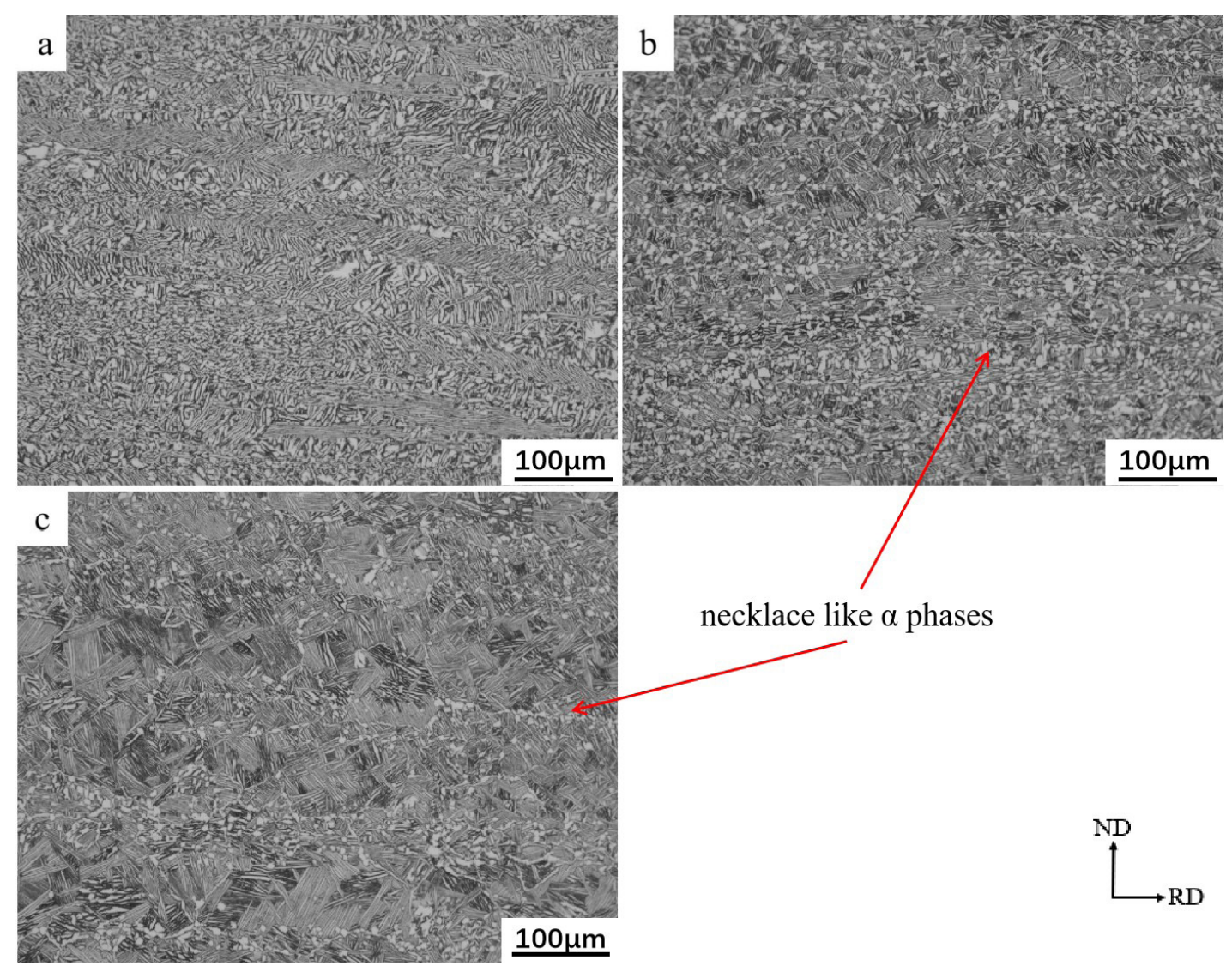

Figure 3. Optical microstructure of Ti80 pipe: (a) as-rolled (b) annealing at $960^{\circ} \mathrm{C} \mathrm{(c)} \mathrm{annealing} \mathrm{at} 990{ }^{\circ} \mathrm{C}$. 
The macrotextures of samples after rolling and subsequent heat treatment are presented as $\{0001\} /\{11-20\}$ pole figures obtained by EBSD, as shown in Figure 4. For the as-rolled sample, it shows a main texture with basal pole perpendicular to the TD direction and located $\sim 40^{\circ}$ away from rolling, which will be referred to as RD-40 in the following. The RD-40 was deformation texture formed during hot rolling, the intensity of which is 10 times random. For the sample annealing at $960^{\circ} \mathrm{C}$, the texture was relatively complex and included different main components. Compared with that after rolling, intensity of the texture decreased to 6 times random after annealing at $960^{\circ} \mathrm{C}$. The main reason for the change of texture could be attributed to the phase transformation after heat treatment, which is explained in section 3.2. In the process of heat treatment, the dissolution of $\alpha$ phases are related with their morphology and crystal orientation, which will lead to the change of texture intensities and components after heat treatment. In particular, as one of the main components, the RD-40 has been preserved after annealing at $960^{\circ} \mathrm{C}$. In the case of $990^{\circ} \mathrm{C}$ annealed sample, the RD-40 has almost disappeared and the main texture components differ greatly from that at $960^{\circ} \mathrm{C}$. Meanwhile, the intensity of the main texture has also increased to 19 times random. In short, different annealing temperature will induce the different intensities and components of texture for Ti80 alloys with bimodal structure.

\subsection{Microtexture of $\alpha$ phases}

To obtain more information about the crystallographic orientation of different microstructures, detailed orientation maps were acquired from smaller representative regions. The euler maps and pole figures at three different conditions were shown in Figure 5, 6, 7. As shown in the $\{0001\}$ pole figures, the main texture components obtained in smaller region are basically the same as that in large region. The representative regions of as-rolled sample has been divided into three areas, including area A, area B and area C. Most $\alpha$ phases have been globularized in area $A$ and area $C$. The $\alpha$ phases in area B are still lamellar structure. The $\{0001\}$ pole figure shows that the RD-40 texture mainly comes from two contributions, one is the lamellar $\alpha$ phases, and the other is some of the globularized $\alpha$ phases. At $960^{\circ} \mathrm{C}$, the $\alpha_{\mathrm{p}}$ and $\alpha_{\mathrm{s}}$ were clearly separated in order to understand their each contributions. It was observed that the RD-40, as a component of main textures of $\alpha_{p}$ phases, was maintained. It was known that the equiaxed $\alpha_{\mathrm{p}}$ in bimodal structure were formed by the globularization and growth of $\alpha_{\mathrm{p}}$ lamellae during deformation and subsequent heat treatment. At the

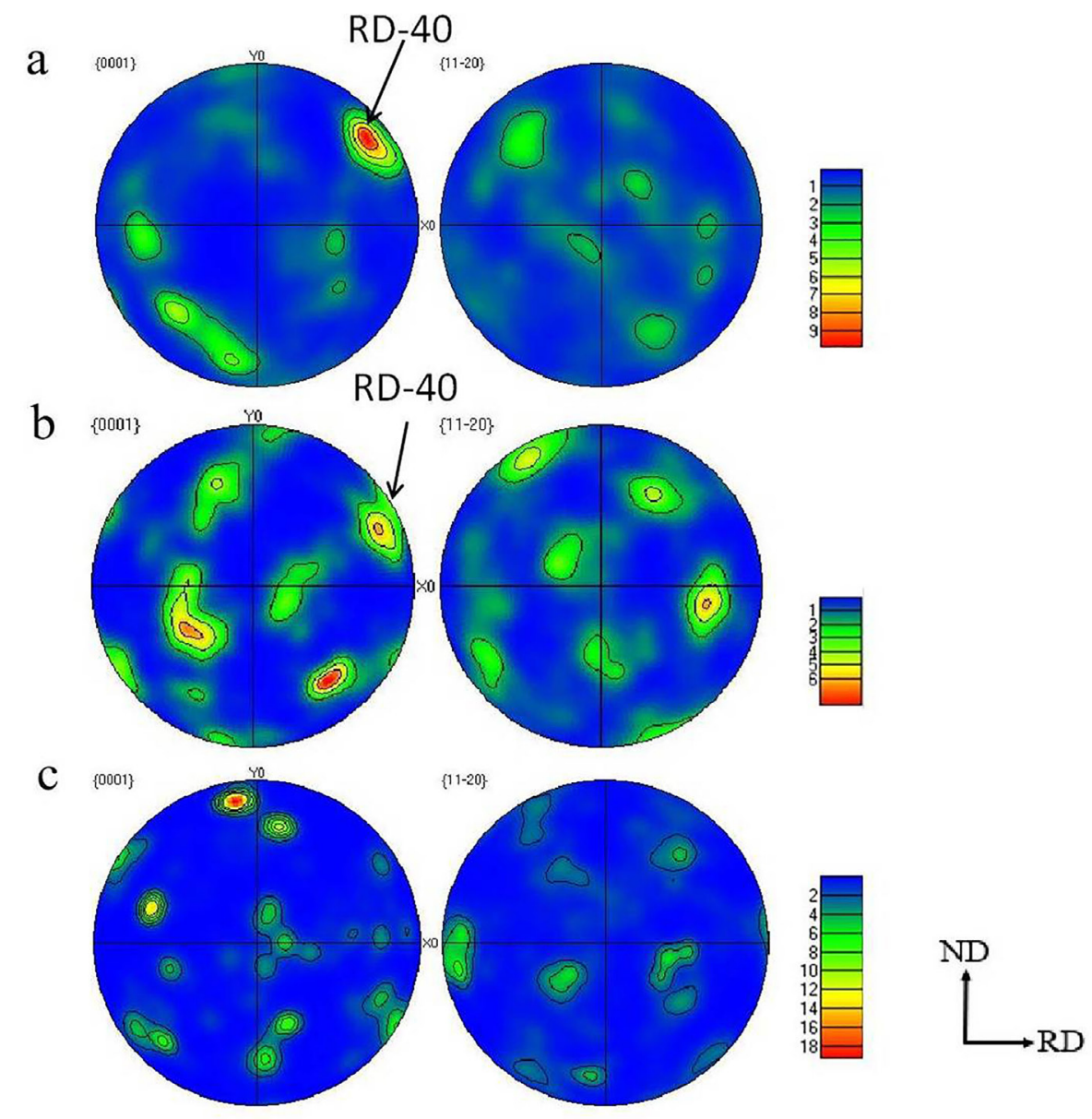

Figure 4. Macrotextures of Ti80 pipe measured using EBSD: (a) As-rolled (b) annealing at $960^{\circ} \mathrm{C}$ (c) annealing at $990{ }^{\circ} \mathrm{C}$. 


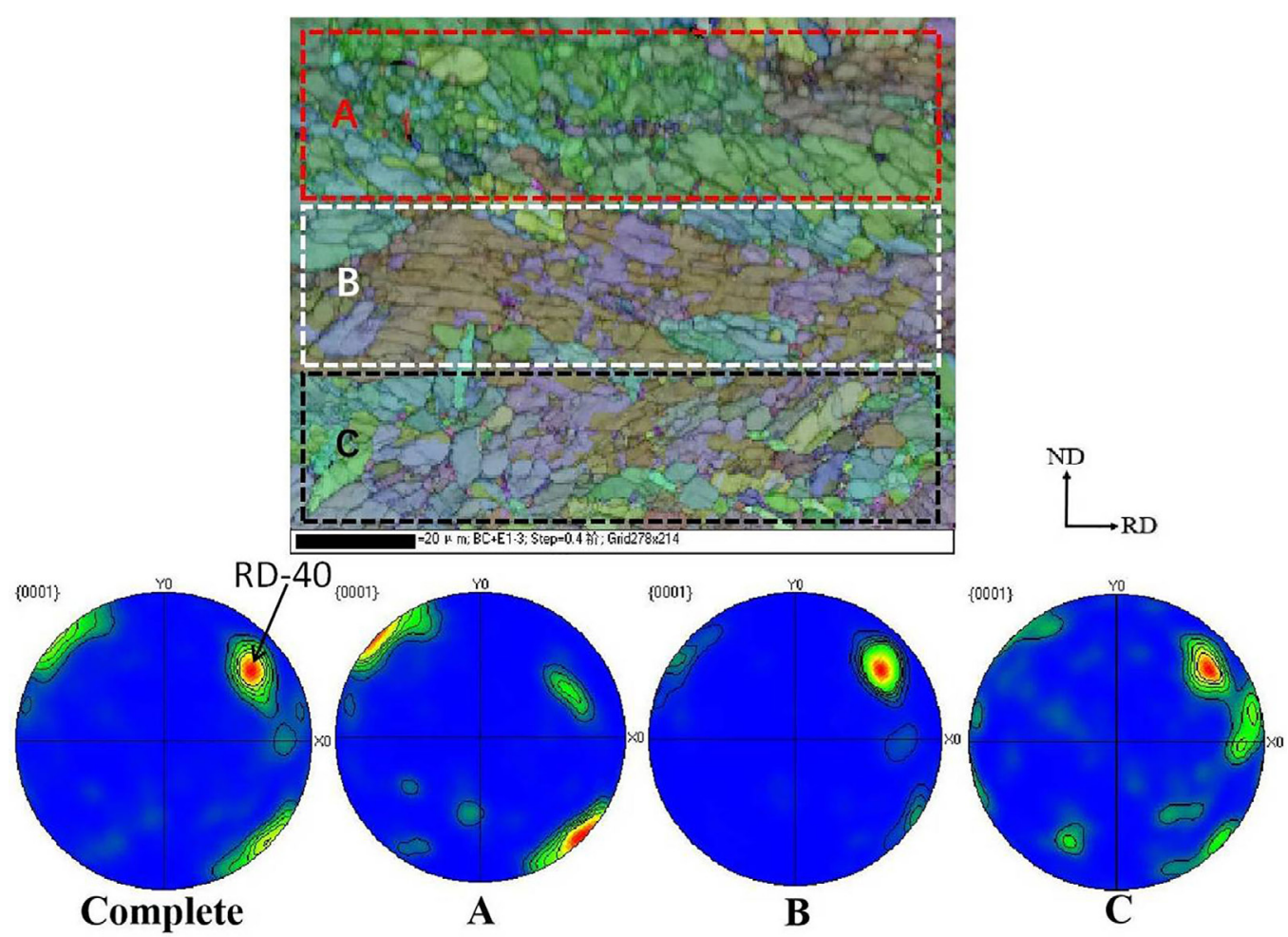

Figure 5. The $\{0001\}$ pole figures of $\alpha$ phase in represent regions for as-rolled Ti80 pipe.

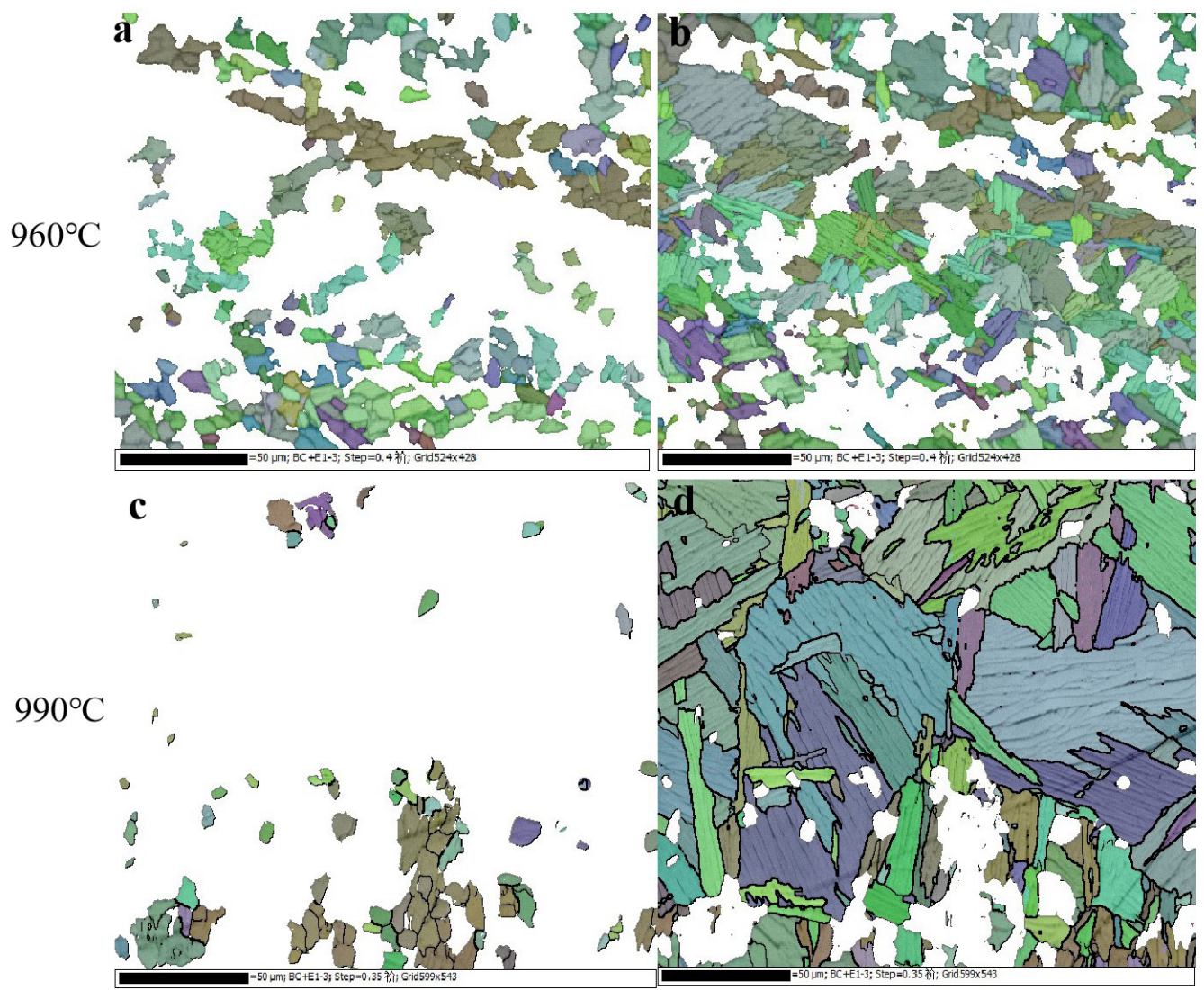

Figure 6. The euler maps of $\alpha_{\mathrm{p}}$ and $\alpha_{\mathrm{S}}$ phases in represent regions: (a) $\alpha_{\mathrm{p}}$ grains at $960^{\circ} \mathrm{C}$, (b) $\alpha_{\mathrm{S}}$ laths at $960^{\circ} \mathrm{C},(\mathrm{c}) \alpha_{\mathrm{p}}$ grains at $990^{\circ} \mathrm{C}$ and (d) $\alpha_{\mathrm{S}}$ laths $990^{\circ} \mathrm{C}$. 


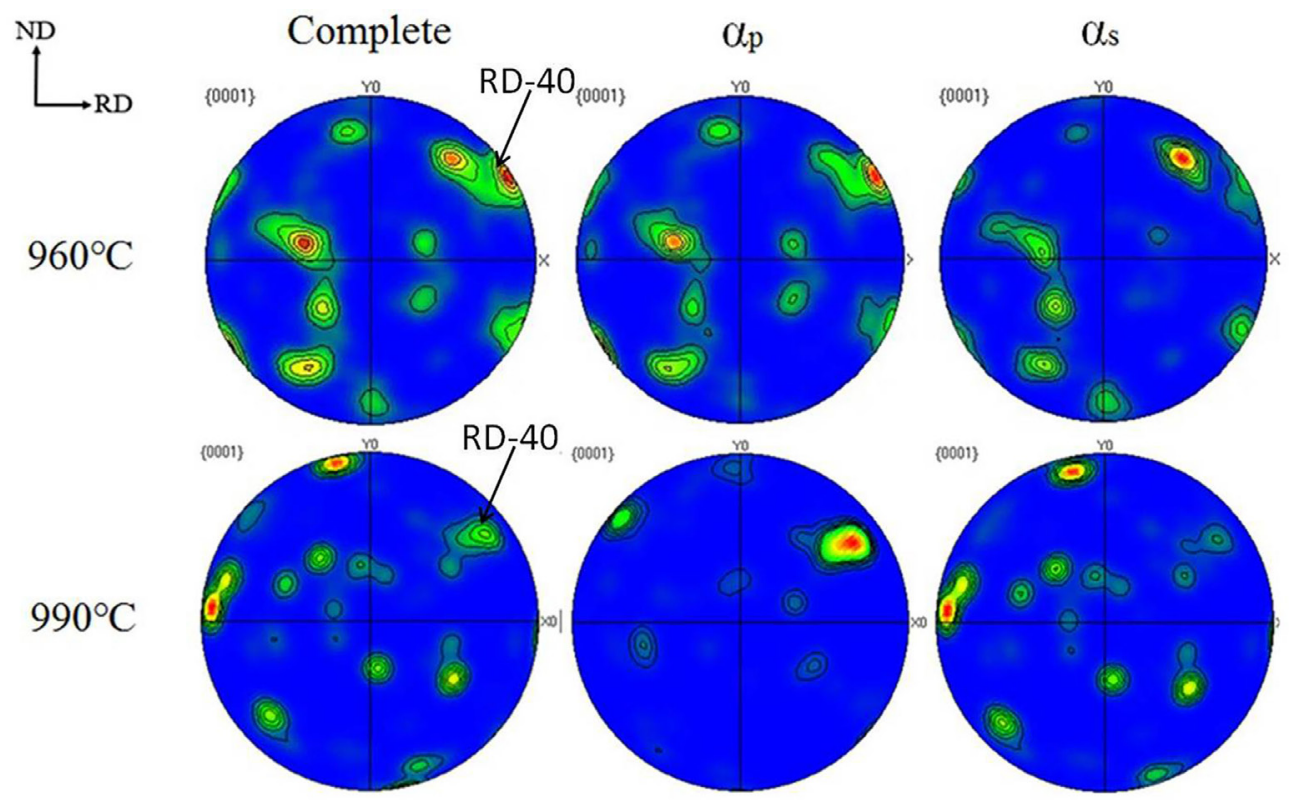

Figure 7. The $\{0001\}$ pole figure maps of $\alpha$ texture from the representative region.

same time, the crystal orientations of $\alpha$ phases were almost unchanged by the static globularization according to Roy's observation $^{22}$. Therefore, the RD-40 has been preserved. Meanwhile, new texture components of $\alpha_{\mathrm{p}}$ appeared after heat treatment at $960^{\circ} \mathrm{C}$. It was because that lamellar structure are more prone to being dissolved compared with equiaxed structure due to higher content of $\alpha$-stable elements ${ }^{23}$. And the lamellar $\alpha$ phases as important components of RD-40 have been dissolved during the heat treatment. Then the texture components became more and the intensities were weakened.

The microtextures of $\alpha_{\mathrm{s}}$ are very close to the corresponding microtextures of $\alpha_{\mathrm{p}}$ at $960^{\circ} \mathrm{C}$, which are similar to other studies ${ }^{17,18}$. Generally, there are two reasons for the closeness between $\alpha_{\mathrm{p}}$ and $\alpha_{\mathrm{S}}$ orientations. At first, the Burgers orientation between $\alpha_{\mathrm{S}}$ and surrounding $\beta$ phases after hot rolling were largely maintained. This was because that some slip systems of $\alpha_{\mathrm{p}}$ and adjacent $\beta$ grains were compatible across the $\alpha_{\mathrm{p}} / \beta$ interfaces during the deformation process ${ }^{24}$. Therefore, the rotations of $\alpha_{\mathrm{p}}$ and $\beta$ grains can be linked during hightemperature deformation. Meanwhile, the holding of Burgers orientation may be related to the invariance of deformation mode and temperature in this study. And the Burgers orientation between $\alpha_{\mathrm{p}}$ and $\beta$ grains would be broken under multiple deformations in different directions ${ }^{19}$. Secondly, the variants with the same orientation as $\alpha_{\mathrm{S}}$ will be preferentially selected during the $\beta \rightarrow \alpha_{S}$ transformation, so that adjacent $\alpha_{\mathrm{p}} / \alpha_{\mathrm{S}}$ have close orientations. This was because the precipitation of $\alpha_{\mathrm{S}}$ phases with close orientations to $\alpha_{\mathrm{S}}$ phases could generate lower interface energy. With the increase of annealing temperature to $990{ }^{\circ} \mathrm{C}$, the microstructure of RD-40 was greatly weakened. It was because that the microtextures of $\alpha_{S}$ were different to that of $\alpha_{\mathrm{p}}$ and the texture of secondary $\alpha$ phases were the main components. It indicated that the precipitation of $\alpha_{S}$ phases was not mainly affected by the $\alpha_{\mathrm{P}}$ phases at $990^{\circ} \mathrm{C}$.
In order to understand the relationship between the textures of $\alpha_{\mathrm{p}}$ and $\alpha_{\mathrm{S}}$ phases with increasing temperature, the statistics of misorientation angles between $\alpha_{\mathrm{p}}$ grains and neighboring $\alpha_{\mathrm{S}}$ were shown in Figure 8 . The results showed that the fraction of the low angle (less than $10^{\circ}$ ) between $\alpha_{\mathrm{p}}$ grains and neighboring $\alpha_{\mathrm{S}}$ decreased from $20.2 \%$ in $960^{\circ} \mathrm{C}$ to $7 \%$ in $990^{\circ} \mathrm{C}$. It indicated that the fraction of $\alpha_{\mathrm{p}}$ grains maintaining Burgers relationship with surrounding $\beta$ matrix decreased with the increasing temperature. Therefore, this would be one factor that caused inconsistency in the textures of the $\alpha_{\mathrm{p}}$ and $\alpha_{\mathrm{s}}$. In addition, the textures of $\alpha_{\mathrm{S}}$ were also affected by its variant selection during cooling from $\beta$ phases. The texture components increased and the intensities were weakened with the decrease of variants selection. In general, the number of different crystallographic orientations varies due to variant selection. Therefore, variant selection can be reflected by the statistical distribution of crystal orientations of correlated grains. The correlated misorientation analysis of the $\alpha$ phases are shown in Figure 9. It could be seen that the low angle boundaries $\left(<10^{\circ} \mathrm{C}\right)$ were more dominant in $960^{\circ} \mathrm{C}$ compared to that in $990^{\circ} \mathrm{C}$. The relative frequency of crystal orientations of $60^{\circ}$ was higher in heat treatment of $990^{\circ} \mathrm{C}$. It was known that angles including $10.5^{\circ}, 60^{\circ}, 60.8^{\circ}$, $63.3^{\circ}$ and $90^{\circ}$ were expected between two $\alpha$ variants within the same $\beta$ grain $^{25}$. Meanwhile, the angle $60^{\circ}, 60.8^{\circ}$ and $63.3^{\circ}$ could not be directly distinguished due to the accuracy of EBSD measurement. Theoretical calculation showed that the relative frequency of $60^{\circ}$ was the highest if there was no variant selection ${ }^{25,26}$. Therefore, variant selection of $\alpha_{\mathrm{S}}$ phases occurred either in $960^{\circ} \mathrm{C}$ and $990^{\circ} \mathrm{C}$. Meanwhile, the degree of variation selection at $960^{\circ} \mathrm{C}$ was higher than that at $990^{\circ} \mathrm{C}$. It was because the $\beta$ grains at $960{ }^{\circ} \mathrm{C}$ were smaller than those at $990^{\circ} \mathrm{C}$ and lamellar $\alpha$ phases were more likely to overgrow the entire grain. Combining with the euler maps (Figure 6), it can be seen that almost all 

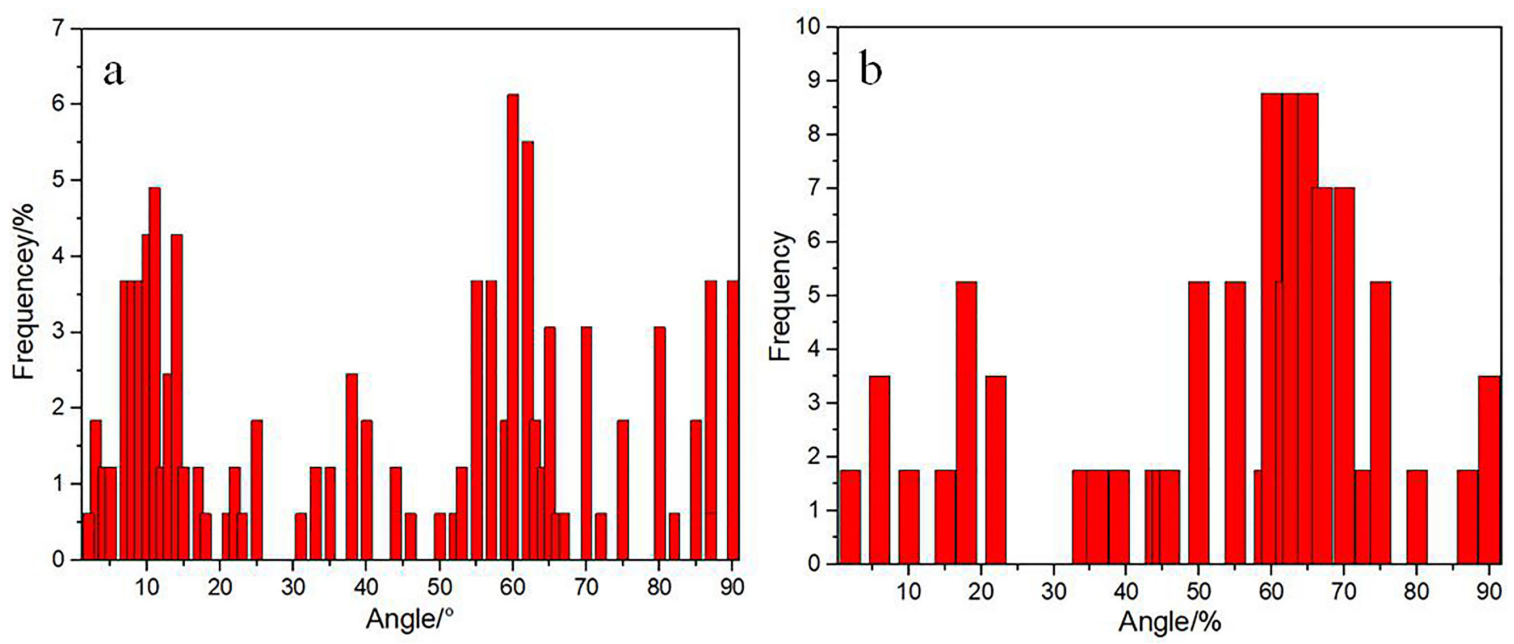

Figure 8. The misorientation angle distribution between $\alpha_{\mathrm{p}}$ and neighboring $\alpha_{\mathrm{S}}$ : (a) $960^{\circ} \mathrm{C}$, (b) $990^{\circ} \mathrm{C}$.

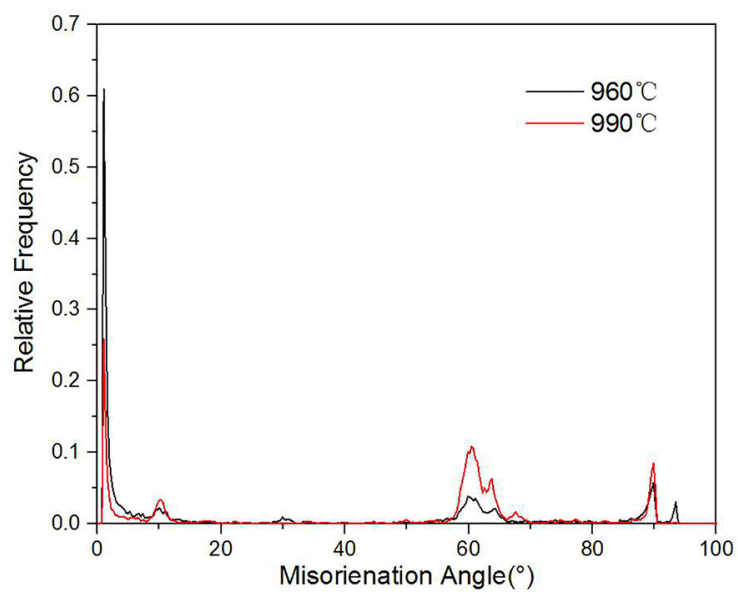

Figure 9. The correlated misorientation angle distribution of the micromaps.

secondary $\alpha$ colonies have close orientation to the adjacent $\alpha_{\mathrm{p}}$ at $960{ }^{\circ} \mathrm{C}$. At the annealing temperature of $990^{\circ} \mathrm{C}$, only some densely distributed $\alpha_{\mathrm{p}}$ exhibited this orientation relationship. For those $\alpha_{\mathrm{p}}$ scattered in the larger $\beta$ grains, they rarely maintained the close orientations to the surrounding $\alpha_{\mathrm{S}}$. It is because that the interfaces between the $\alpha_{\mathrm{p}}$ and the surrounding $\beta$ phase decreased with decreasing $\alpha_{\mathrm{p}}$ grains. And decreasing interfaces would induce insufficient driving force for the precipitation of $\alpha_{\mathrm{S}}$ with similar orientations. Therefore, the growth of recrystallized $\beta$ grains as well as the decreasing number of $\alpha_{\mathrm{p}}$ would greatly reduce the effect of $\alpha_{\mathrm{p}}$ on the variant selection of $\alpha_{\mathrm{S}}$. The critical content of the $\alpha_{\mathrm{p}}$ that affects the final texture would be the subject of our future research.

In summary, the microtextures of $\alpha_{\mathrm{p}}$ were mainly affected by the initial texture and the dissolution degree of $\alpha$ phases during subsequent heat treatment. Meanwhile, the microtextures of $\alpha_{\mathrm{S}}$ were greatly affected by the orientations of $\alpha_{p}$ when the recrystallized $\beta$ grains were relatively small. With the increase of temperature and growth of recrystallized $\beta$ grains, the main factor affecting the final texture changed from $\alpha_{\mathrm{p}}$ to recrystallized $\beta$ grains.

\subsection{The morphology and texture evolution of $\beta$ grains}

As mentioned above, the microstructure and texture evolution of the $\alpha$ phases also were influenced by the $\beta$ phases. As a near $\alpha$ alloy, only a little fraction of $\beta$ phases remained at room temperature for Ti80 pipe. To understand the reasons for texture evolution with the increase of annealing temperature, the pole figures and inverse pole figures of original $\beta$ grains (Figure 10,11c, d) after heat treatment were reconstructed from measured $\alpha_{\mathrm{S}}$ orientation. For the as-rolled samples, the pole figure of high temperature $\beta$ phase was obtained by a small amount of residual phases at room temperature. It was because that only a small amount of $\beta$ phases existed during rolling at $930^{\circ} \mathrm{C}$. Figure 10 shows that the $\beta$ textures changes significantly with the increasing annealing temperature. There are three main components in 100 pole figures for samples after rolling and annealing at $960^{\circ} \mathrm{C}$. At the same time, the three components are perpendicular to each other in the 100 pole figure. It means that these three components correspond to an euler angle. As the annealing temperature rose to $990^{\circ} \mathrm{C}$, the components of $\beta$ texture were more than that in $960^{\circ} \mathrm{C}$, and the intensity of the main texture also increased.

The evolution of $\beta$ grain morphology should be studied to understand the formation of $\beta$ textures. As shown in Figure $11 \mathrm{c}, \mathrm{d}$, the reconstructed $\beta$ grains were elongated with the same direction of the $\alpha_{\mathrm{p}}$ grains of necklace shape at the annealing temperature of $960^{\circ} \mathrm{C}$. The width of $\beta$ grains was about $30 \sim 50 \mu \mathrm{m}$, which was consistent with that of the secondary $\alpha$ colonies after deformation. It was observed that a large amount of $\alpha_{\mathrm{p}}$ grains located in the boundaries of different $\beta$ grains. It indicated that the recrystallization of $\beta$ grains occurred and the growth of grains was hindered when encountered the $\alpha$ phases with no Burgers relationship due to the pinning effect in the process of heat treatment ${ }^{27}$. At the annealing temperature of $990^{\circ} \mathrm{C}$, the size of the $\beta$ grains further increased due to the dissolution of more $\alpha_{\mathrm{p}}$. And the 


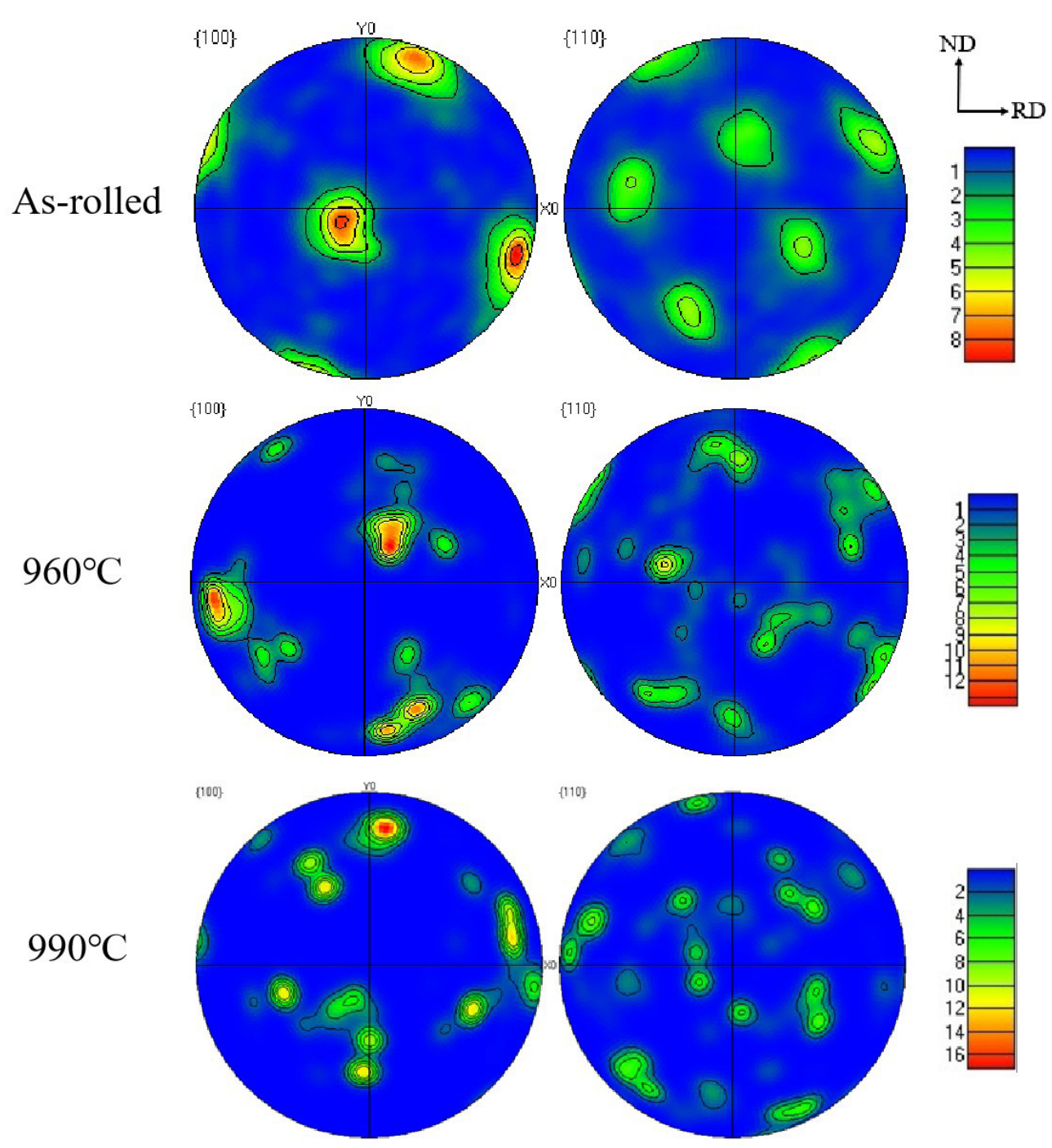

Figure 10. Pole figure maps from the reconstructed $\beta$ grains: (a) As-rolled, (b) $960^{\circ} \mathrm{C}$, (c) $990^{\circ} \mathrm{C}$.

grain coarsening of $\beta$ grains could strengthen specific $\beta$ texture components ${ }^{28}$. Then the stronger $\beta$ texture leads to the stronger texture of $\alpha$ phases at $990^{\circ} \mathrm{C}$.

As mentioned above, the formation of $\beta$ phases at $960^{\circ} \mathrm{C}$ would be related to the prior $\beta$ grains after rolling according to similar morphology. It could be seen that the textures of $\beta$ phases after heat treatment were completely different from those after rolling. Meanwhile, only one $\alpha$ variant maintained the Burgers relationship with the $\beta$ phases for the as-rolled sample, and more $\alpha_{\mathrm{p}}$ variants held the Burgers relationship with surrounding $\beta$ phases after heat treatment, as shown in Figure 4 and 10. Therefore, it can be deduced that the $\beta$ phases at high temperature were not only from the growth of residual $\beta$ phases at room temperature. It were mainly formed by the transformation of $\alpha$ phases at room temperature. In addition, it could be seen that the $\alpha_{\mathrm{p}}$ grains of necklace shape have the same orientation according to the former euler map. And most of the necklace like $\alpha_{\mathrm{p}}$ grains maintained the Burgers relationship with surrounding $\beta$ grains according to the statistics, as shown in Figure 11a, b. The fraction of $\alpha_{\mathrm{p}}$ grains maintaining Burgers relationship with $\beta$ phases decreased as the annealing temperature increased from $960^{\circ} \mathrm{C}$ to $990^{\circ} \mathrm{C}$. This can be explained by that the $\alpha$ phases holding Burgers relationship with adjacent $\beta$ phases were more prone to phase transition. Combining with the microstructure, it could be known that these necklace like $\alpha$ grains were formed by the globularization of $\alpha$ colonies in the original $\beta$ grains after rolling. And the elongated $\beta$ grains were transformed from the original $\alpha$ colonies within deformed $\beta$ grains. Meanwhile, it should be mentioned that the difference of $\beta$ textures at different annealing temperature may be caused by two factors, one was the variant selection of $\beta$ phases at different annealing temperatures, and the other was the change of crystal orientations during the growth of $\beta$ grains. The mechanism still needs further study.

The research in this paper shows that three main methods could be used to reduce the texture intensities of Ti80 pipe after heat treatment. Firstly, the area of $\alpha_{S}$ colonies before rolling must be reduced. Secondly, the $\alpha_{\mathrm{S}}$ colonies should be broken as much as possible during the rolling process. 


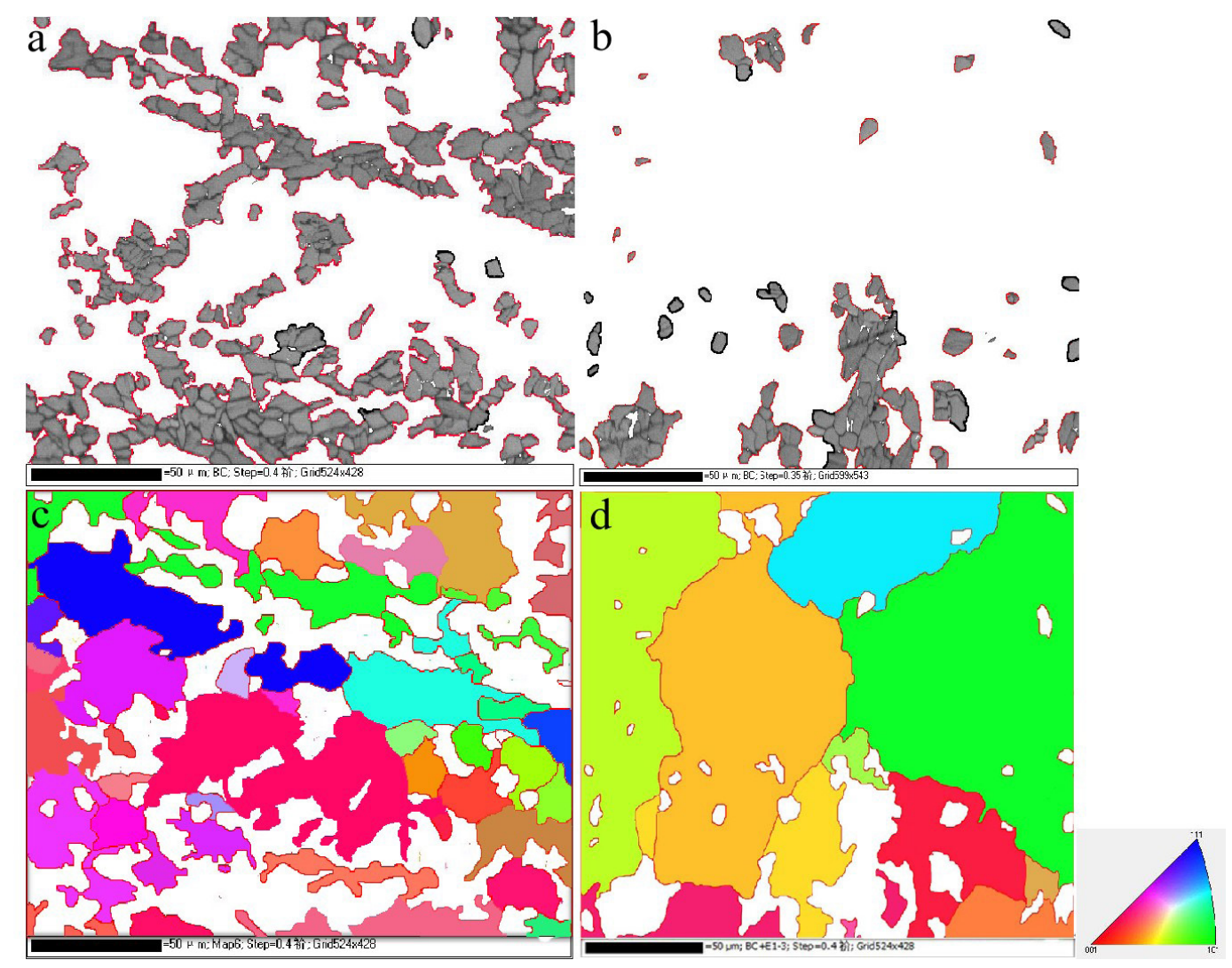

Figure 11. The statistics of $\alpha_{\mathrm{p}}$ grains maintaining Burgers relationship with neighboring $\beta$ grains at $960{ }^{\circ} \mathrm{C}$ (a) and $990^{\circ} \mathrm{C}$ (b). Note: Burgers relationship and Non-Burgers relationship was depicted as red lines and black lines, respectively. The inverse pole figures of reconstructed $\beta$ grains: (c) $960^{\circ} \mathrm{C},(\mathrm{d}) 990^{\circ} \mathrm{C}$.

Finally, the size of $\beta$ grains should be controlled during the subsequent heat treatment.

\section{Conclusion}

A study has been conducted to understand the evolution of microstructure and texture of hot-rolled Ti80 pipe during heat treatment. The following conclusions were drawn.

(1) The as-rolled Ti80 pipe shows a main texture with basal pole perpendicular to the TD direction and located $\sim 40^{\circ}$ away from rolling direction. The crystal orientation $\alpha_{\mathrm{p}}$ were not changed during the heat treatment. This texture has been preserved in the pole figure of $\alpha_{p}$ with the increase of annealing temperature. The dissolution of $\alpha_{\mathrm{p}}$ induce the increase of $\alpha$ texture components at annealing of $960^{\circ} \mathrm{C}$.

(2) The textures of $\alpha_{\mathrm{s}}$ are very close to that of $\alpha_{\mathrm{p}}$ at the heat treatment of $960^{\circ} \mathrm{C}$. When the annealing temperature increased to $990^{\circ} \mathrm{C}$, the textures of $\alpha_{\mathrm{s}}$ were not mainly affected by the crystal orientation of $\alpha_{\mathrm{p}}$. The necklace like $\alpha$ phases were transformed from the globularization of $\alpha$ colonies within prior $\beta$ grains after rolling. The fraction of $\alpha_{\mathrm{p}}$ maintaining Burgers relationship with $\beta$ phases decreased as the annealing temperature increased from $960^{\circ} \mathrm{C}$ to $990^{\circ} \mathrm{C}$.

(3) The morphology of reconstructed $\beta$ grains were similar to the prior $\beta$ grains after rolling at the heat treatment of $960^{\circ} \mathrm{C}$. And the growth of recrystallized $\beta$ grains were hindered in the vertical direction of rolling by the necklace like $\alpha$ phases due to the pinning effect during the process of heat treatment. The textures of $\beta$ phases were greatly influenced by the annealing temperature and the $\beta$ phases at high temperature were mainly formed by the transformation of $\alpha$ phases at room temperature.

\section{Acknowledgement}

The work is financially supported by the Program of National Key Research and Development Plan of China (NO.2016YFB0301203). In addition, this work was supported by Aeronautical Science Foundation of China (No. 201911053001), National Natural Science Foundation of China (NO. 51905436), and Natural Science Foundation of Shaanxi province of China (2020JQ-156).

\section{References}

1. Gao XX, Zeng WD, Wang YB, Long Y, Zhang S, Wang Q. Evolution of equiaxed alpha phase during heat treatment in a near alpha titanium alloy. J Alloys Compd. 2017;725:536-43.

2. Golaz B, Michaud V, Lavanchy S, Månson J-AE. Design and durability of titanium adhesive joints for marine applications. Int J Adhes Adhes. 2013;45:150-7. 
3. Hasson DF, Crowe CR. Titanium for offshore oil drilling. JOM. 1982;34(1):23-8.

4. Jia R, Zeng W, He S, Gao X, Xu J. The analysis of fracture toughness and fracture mechanism of Ti60 alloy under different temperatures. J Alloys Compd. 2019;810:151899.

5. Zhang SF, Zeng WD, Zhao QY, Gao X, Wang Q. High cycle fatigue of isothermally forged Ti-6.5Al-2.2Mo-2.2Zr-1.8Sn$0.7 \mathrm{~W}-0.2 \mathrm{Si}$ with different microstructures. J Alloys Compd. 2016;689:114-22.

6. Shi XH, Zeng WD, Shi CL, Wang H, Jia Z. The fracture toughness and its prediction model for $\mathrm{Ti}-5 \mathrm{Al}-5 \mathrm{Mo}-5 \mathrm{~V}-1 \mathrm{Cr}-1 \mathrm{Fe}$ titanium alloy with basket-weave microstructure. J Alloys Compd. 2015;632:748-55.

7. Zhang SF, Zeng WD, Zhao QY, Ge L, Zhang M. In situ SEM study of tensile deformation of a near- $\beta$ titanium alloy. Mater Sci Eng A. 2017;708:574-81.

8. Singh AK, Schwarzer RA. Evolution of texture during thermomechanical processing of titanium and its alloys. Trans Indian Inst Met. 2008;61(5):371-87.

9. Mironov S, Murzinova M, Zherebtsov S, Salishchev GA, Semiatin SL.Microstructure evolution during warm working of Ti-6Al-4V with a colony- $\alpha$ microstructure. Acta Mater. 2009;57(8):2470-81.

10. Roy S, Suwas S. Microstructure and texture evolution during sub-transus thermomechanical processing of Ti-6Al-4V-0.1B alloy: part i. hot rolling in $(\alpha+\beta)$ phase field. Metall Mater Trans, A Phys Metall Mater Sci. 2013;44(7):3303-21.

11. Roy S, Karanth S, Suwas S. Microstructure and texture evolution during sub-transus thermo-mechanical processing of Ti-6Al4V-0.1B alloy: part ii. static annealing in $(\alpha+\beta)$ regime. Metall Mater Trans, A Phys Metall Mater Sci. 2013;44(7):3322-36.

12. Bantounas I, Dye D, Lindley TC. The role of microtexture on the faceted fracture morphology in Ti-6Al-4V subjected to high-cycle fatigue. Acta Mater. 2010;58(11):3908-18.

13. Zhao ZB, Wang QJ, Hu QM, Liu JR, Yu BB, Yang R. Effect of $\beta$ (110) texture intensity on $\alpha$-variant selection and microstructure morphology during $\beta \rightarrow \alpha$ phase transformation in near $\alpha$ titanium alloy. Acta Mater. 2017;126:372-82.

14. Stanford N, Bate PS. Crystallographic variant selection in Ti-6Al-4V. Acta Mater. 2004;52(17):5215-24.

15. Obasi GC, Fonseca JQ, Rugg D, Preuss M. The effect of $\beta$ grain coarsening on variant selection and texture evolution in a near- $\beta$ Ti alloy. Mater Sci Eng A. 2013;576:272-9.
16. Obasi GC, Moat RJ, Prakash DGL, Kockelmann W, Fonseca JQ, Preuss M. In situ neutron diffraction study of texture evolution and variant selection during the $\alpha \rightarrow \beta \rightarrow \alpha$ phase transformation in Ti-6Al-4V. Acta Mater. 2012;60(20):7169-82.

17. Germain L, Gey N, Humbert M, Vo P, Jahazi M, Bocher P. Texture Heterogeneities induced by subtransus Processing of near alpha Titanium alloys. Acta Mater. 2008;56(16):4298-308.

18. Leo Prakash DG, Honniball P, Rugg D, Withers PJ, Quinta da Fonseca J, Preuss M. The effect of $\beta$ phase on microstructure and texture evolution during thermomechanical processing of $\alpha+\beta$ Ti alloy. Acta Mater. 2013;61(9):3200-13.

19. Zhao ZB, Wang QJ, Liu JR, Yang R. Effect of heat treatment on the crystallographic orientation evolution in a near- $\alpha$ titanium alloy Ti60. Acta Mater. 2017;131:305-14.

20. Glavicic MG, Kobryn PA, Bieler TR, Semiatin SL. A method to determine the orientation of the high-temperature beta phase from measured EBSD data for the low-temperature alpha phase in Ti-6Al-4V. Mater Sci Eng A. 2003;346(1-2):50-9.

21. Bieler TR, Semiatin SL. The origins of heterogeneous deformation during primary hot working of Ti-6Al-4V. Int J Plast. 2002;18(9):1165-89.

22. Roy S, Suwas S. Orientation dependent spheroidization response and macro-zone formation during sub $\beta$-transus processing of Ti-6Al-4V alloy. Acta Mater. 2017;134:283-301.

23. He ST, Zeng WD, Xu J, Chen W. The effects of microstructure evolution on the fracture toughness of BT-25 titanium alloy during isothermal forging and subsequent heat treatment. Mater Sci Eng A. 2019;745:203-11.

24. Suri S, Viswanathan GB, Neeraj T, Hou D-H, Mills MJ. Room temperature deformation and mechanisms of slip transmission in oriented single-colony crystals of an $\{$ alpha $\} /$ \{beta $\}$ titanium alloy. Acta Mater. 1999;47(3):1019-34.

25. Wang SC, Aindow M, Starink MJ. Effect of self-accommodation on $\alpha / \alpha$ boundary populations in pure titanium. Acta Mater. 2003;51(9):2485-503.

26. Bohemen SMC, Kamp A, Petrov RH, Kestens LAI, Sietsma $J$. Nucleation and variant selection of secondary $\alpha$ plates in a $\beta$ Ti alloy. Acta Mater. 2008;56(20):5907-14.

27. Nishizawa $T$. Thermodynamics of microstructure control by particle dispersion. ISIJ Int. 2000;40(12):1269-74.

28. Obasi GC, Birosca S, Fonseca JQ. The influence of rolling temperature on texture evolution and variant selection during $\alpha \rightarrow \beta \rightarrow \alpha$ phase transformation in Ti-6Al-4V. Acta Mater. 2012;60:1048-58. 